\title{
Management System Certification Benefits: Where Do We Stand?
}

Luis Miguel Ciravegna Martins da Fonseca ${ }^{1}(\mathbb{D})$, José Pedro Domingues ${ }^{2}$ (D) , Pilar Baylina Machado ${ }^{3}$, Mario Calderón ${ }^{4}$

${ }^{1}$ ISEP, Porto School of Engineering, P. Porto and CIDEM Researcher (Portugal)

${ }^{2}$ ISEP, Porto School of Engineering, P. Porto (Portugal)

${ }^{3}$ ESS, School of Health, P. Porto (Portugal)

${ }^{4}$ Rey Juan Carlos University and AENOR - Spanish Association for Standardisation and Certification (Spain)

Imf@,isep.ipp.pt,jpd@,isep.ipp.pt,pbm@,ess.ipp.pt, mcalderon@,aenor.com

Received: May 2017

Accepted: July 2017

\section{Abstract:}

Purpose: The implementation and certification of Management Systems International Standards, such as ISO 9001 and ISO 14001, achieved a high international recognition, with more than 1 million organizations with their Quality Management Systems certified worldwide. Researchers have been paying considerable attention to this theme and the number of published articles has robustly grown. Although on an overall basis, the research results support the existence of positive impacts on the adoption and certification of these International Standards, there are various inconsistencies and contradictory results, leading to some controversy over its impacts for organizations. This study aims to bring a longitudinal time perspective to this area of research, analyzing the articles published since 1996, on the benefits of Management Systems Certification. A longitudinal perspective of countries of authors origin, keywords and journals is presented, complemented with an evaluation of the research results.

Design/methodology/approach: A Bibliometric Study supported the research, with data collected from Web of Science, SCOPUS, and Research Gate data bases. Following the detailed analysis of the journal titles, articles abstracts and their full content, an evaluation scale was adopted to assess if the results support the existence of a positive relationship between Management System Certification and economic, financial or stakeholder results. 
Findings: The results evidence a steep increase in the number of publications addressing Management Systems Certification benefits, that mainly originate from Europe (48\%) and East Asia and Pacific (23\%), with Spain as the leading country (accounting for 14\% of the total number of articles published between 1996 and April 2017). Journal of Cleaner Production (Environmental Management System Certification) and Total Quality Management and Business Excellence journal (Quality Management Systems Certification) are the leading journals for disseminating the research and the most used keywords are "Quality/Environment", "ISO 9001/14001", "Performance", "Management Systems" and "Certification". There are also insights that the research is now open to other Management Systems either than Quality and Environment. The systematic review of the selected papers shows that the Management Systems adoption and certification brings fairly positive benefits (average 2,34 in a 1 to 5 Likert type scale) for the certified organizations, although some variations are observed. Some avenues for future research should consider the reliability and validation of measures; sampling and biases errors; the identification of control, moderating and mediating variables; the consideration of time and situational contingencies; and the search for explanations for cause and effect relationships.

The results of this research support the view that the investigation of Management Systems Certification benefits is indeed an issue of high academic and practitioners interest. This research, although subject to some subjective evaluation of the authors, and acknowledging that the research articles are not always comparable, aims to give some insights for this continuous research field.

Research limitations/implications: Although the authors took measures to minimize subjectivity, it should be noted that the evaluation could be subject to the authors own interpretation and the research articles are not always comparable.

Originality/value: This research presents a longitudinal and comprehensive evaluation of the articles published since 1996 addressing the topics of the benefits of Management System Certification. It highlights trends and gives contribution for future research, on a field of intense academic and practitioners interest.

Keywords: management systems, certification, benefits, systematic review; ISO, bibliometric study 


\section{Introduction}

In the quest to create, deliver and capture value and sustain superior performance and business results, more than 1 million organizations have implemented and are certified according to ISO Management Systems Standards (MSSs), on a worldwide basis and across all activity sectors. International Management Standards establish ways to systematize the organizational processes and provide documented information on their management and results. They cover different areas such as quality, environment, health and safety, information security, and social responsibility. From the several ISO International Management Systems Standards, ISO 9001: Quality Management Systems - Requirements and ISO 14001: Environmental Management Systems - Requirements, are the two most widely used, although in the last years several other International Management Systems Standards, such as, ISO 50001, ISO 27001, ISO 22000, ISO/TS 16949, ISO 13485, ISO 22301, and ISO 20000-1, have gained increased adoption (ISO, 2016).

Empirical studies on MSSs started by addressing the organizations motivations to implement the standard, usually followed by the implementation process and its impact of the standard (Karapetrovic, Casadesus \& Heras, 2010).

Research supports the view that Quality Management Systems (QMS) can bring significant benefits for organizations competitiveness and success, by helping them to operate efficiently and respond to customer and key stakeholder requirements (Tarí, Molina-Azorín \& Heras, 2012). Internal motivations to implement ISO 9001 can foster organizational and process improvements which may contribute to better quality and customer satisfaction, contributing to better financial performance and competitive position. External motivation can improve the access to markets, satisfy customer requirements, enhance the organization image, and facilitate the access to governmental incentives, but if no internal improvements are implemented, and the goal is just to do the minimum to achieve certification, the external benefits might not endure (Llopis \& Tari, 2003; Boiral \& Roy, 2007); Martínez-Costa, Martínez-Lorente \& Choi, 2008; Prajogo, 2011). However, it should be acknowledged that there are authors that favor the benefits of the internal motivations for MSSs implementation and certification, while others consider the external motivations as more relevant. And while most authors support the positive effects of Management Systems Standards Certification (MSSC) a few report negative effects (Tarí et al., 2012) probably due to the way the MSS was interpreted and implemented and/or methodological issues.

The goal of this investigation is to use a methodology that can bring a systemic and longitudinal perspective in the research of Management Systems certification benefits. 


\section{Background}

Since the first edition of the ISO 9000 series, in 1987, ISO 9001 Quality Management Systems (QMS) have been adopted by more than 1 million organizations of all activity sectors, on a worldwide basis (Fonseca, 2015a). This impressive movement as lead to a strong mainstream of research on the benefits of QMS (Tarí et al., 2012) and Environmental Management Systems (EMS) implementation and certification.

A common characteristic of International Management Systems Standards is that the implementation of their requirements can be audited and certified by an independent external entity. To have its Management System (MS) certified, either Quality, Environmental, Health and Safety or other, an organization has its MS audited by an independent certification body (called the CB - certification body), to assess if it complies with the applicable International Standard requirements and achieves the intended results. Following the successful certification, the $\mathrm{CB}$ issues a certificate of conformity allowing the certified organization to evidence that it has implemented the standard and is successfully operating the applicable management system. The certification body should demonstrate that it has competent management and staff and that it is impartial and free from conflicts of interest. To that end, the accreditation bodies audit certification bodies against ISO/IEC 17021-1:2015 standard and an accredited certification body should fulfill the applicable requirements and generate confidence to its stakeholders.

Researchers have extensively studied the benefits of ISO 9001 certification, e.g. Karapetrovic et al. (2010) identified more than 100 empirical studies investigating the impact of ISO 9000 standards worldwide.

According to Casadesús, Heras and Ochoa (2000) and Boiral (2012), ISO 9001 certification can have both internal (e.g., improved product quality, short delivery times, cost reductions, better process performance, improved system documentation, and higher quality awareness), and external benefits (e.g., improved customer satisfaction, better market image and stronger competitive position). The success in the implementation of ISO 9001 QMS is linked to the organization motivations (most significant results when the motivations are internal rather than external) and to the way the standard is interpreted (Fonseca, 2015b).

Although the research in the benefits of Management Systems Certification (MSC) points to the existence of a positive relationship between MSC and organizational performance $(\mathrm{P})$ and results, there are some inconsistencies and several studies that have found a neutral or even negative relationship between MSC and organizational performance and results.

These inconsistencies might be explained by concerns over reliability and lack of validation of measures, sampling, and biases errors (e.g., Quality Managers might report more favorable impacts of QMS than CEOs), the absence of control variables and no explanations for cause and effect relationships. Time is 
also an important variable to be considered, as some benefits can be realized on the short term oriented (e.g. compliance with customer requirements) while others only on the long term (e.g., company image and reputation). Also, financial performance is more focused on the firms' short term financial results, while some quality or environmental initiatives are more long-term oriented and potentially reflected on qualitative non-financial indicators (e.g., customer satisfaction, brand image and corporate reputation, employees' motivation, quality of products or services, etc.).

There are mediating and moderating variables (e.g. stakeholder results) and situational contingencies that can influence the MSC-P relationship, e.g. investing in improving quality and environment performance has positive effects on intangibles that might lead to superior levels of corporate financial performance.

When the subject is relevant and there is no consensus on the benefits of its application, there is a research opportunity to fulfil this knowledge gap. The purpose of this study is to perform a Bibliometric Study of the benefits of Management Systems Certification (MSC) and identify the articles that access the benefits of MSC, the longitudinal time evolution of the countries of origin and respective authors, keywords adopted, and the journals in which they were published. Additionally, an evaluation of the level of support of the research results concerning positive benefits of MSC was carried out.

\section{Research Design}

This type of Bibliometric studies aims to evaluate the scientific activity of a field of study by performing a meta-analytical research of literature (Kim \& McMillan, 2008) by analyzing published data and identifying information such as authorship, affiliation, citations, and keywords (De Bellis, 2009), researching for statistical behaviors of the object of the research over a specific time (Herrero-Prieto, 2009).

Usually, a Bibliometric Study is used to evaluate and monitor the state of a field over time, evaluating the development of a given research area (Fetscherin \& Heinrich, 2015). It seeks to analyze the quantity rather than the quality of the scientific production, however, the author(s) will take into consideration the specific journal impact factors as a proxy for article quality. The scope of this study is the analysis of research scientific articles that use scientific journals as their mean of communication, as a "certified source of knowledge" that is statistically representative of the subject under research (Ramos-Rodríguez \& Ruiz-Navarro, 2008).

Data was collected from Web of Science, SCOPUS, and Research Gate data bases in April 2017 by searching with the strings "management systems", "certification"," benefits" and "management systems certification AND benefits", applied to topics and journals in English that were published from 1996. 
The results yielded a total of 259 articles, from 699 authors, published in 132 scientific journals, from 1998 to April 2017.

Next steps were to analyze the articles titles, the abstracts, and their full contents, by applying the evaluation Likert Type scale presented in Table 1. The purpose was to assess if the results support "the existence of a positive relationship between Management System Certification (MSC) and economic, financial or stakeholder results":

\begin{tabular}{|l|c|}
\hline No evidence of positive relationship of MSC in economic, financial or stakeholder results & $1(0 \%)$ \\
\hline $\begin{array}{l}\text { Evidence of positive relationship of MSC in some of the economic, financial or stakeholder } \\
\text { results }\end{array}$ & $2(25 \%)$ \\
\hline $\begin{array}{l}\text { Evidence of positive relationship MSC in at least half of the relevant economic, financial and } \\
\text { stakeholder results }\end{array}$ & $3(50 \%)$ \\
\hline $\begin{array}{l}\text { Evidence of positive relationship of MSC in most of the relevant economic, financial and } \\
\text { stakeholder results }\end{array}$ & $4(75 \%)$ \\
\hline $\begin{array}{l}\text { Evidence of strongly positive relationship of MSC in the relevant economic, financial and } \\
\text { stakeholder results }\end{array}$ & $5(100 \%)$ \\
\hline
\end{tabular}

Table 1. Evaluation scale to access benefits of MSC 


\section{Results}

\subsection{Global Management System Certification}

Figure 1 shows a steep increase in the number of publications on Management Systems Certification (MSC) with a more than tenfold growth in the last 10 years.

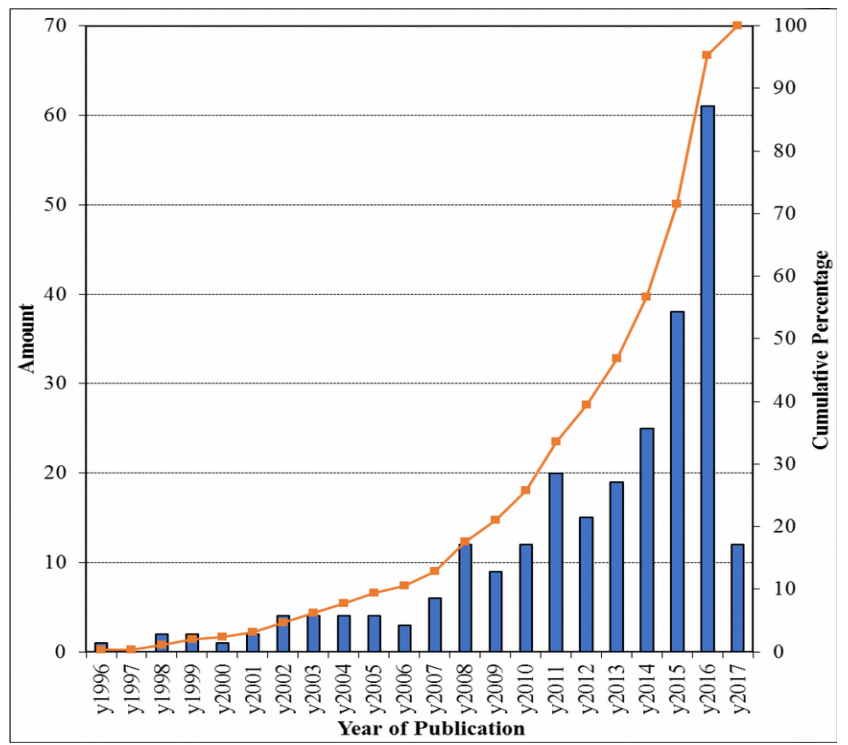

Figure 1. Number of articles per year in the field of MSC

Geographically and adopting the same World Macro Regions as those in the ISO Survey of certification (ISO, 2016), the MSC articles originated mainly from Europe, followed and East Asia and Pacific, as presented in Figure 2.

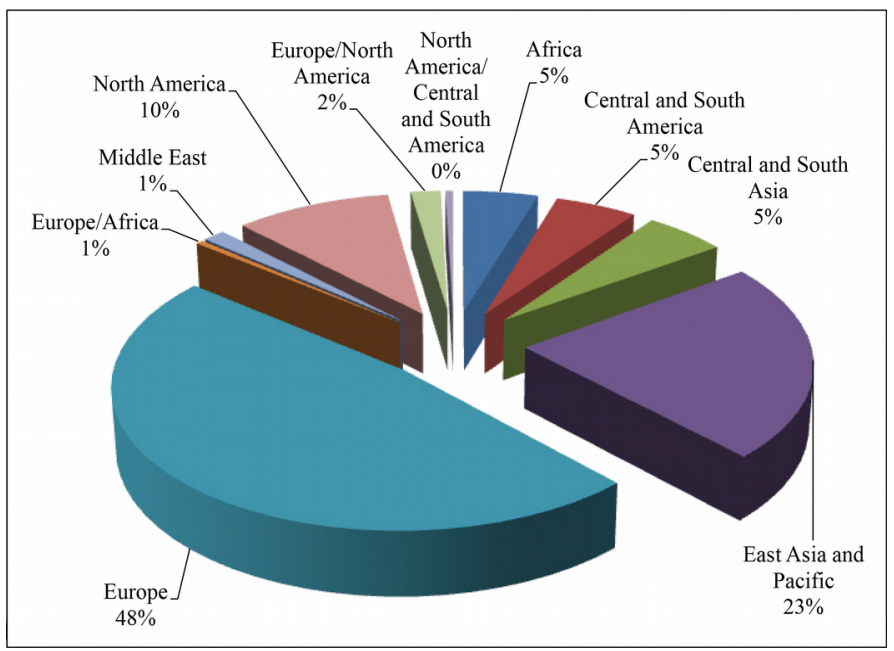

Figure 2. World Macro Regions share of geographical locations of authors of articles with the topic MSC articles 
Specifically concerning authors country of origin, Spain accounts for $14 \%$ of the total number of MSC articles for the period between 1996 and April 2017 and the total 10 more representative countries (Spain, USA, Malaysia, Italy, China, Brazil, Portugal, Greece, Australia, Croatia) represent $52 \%$ of the total (Figure 3).

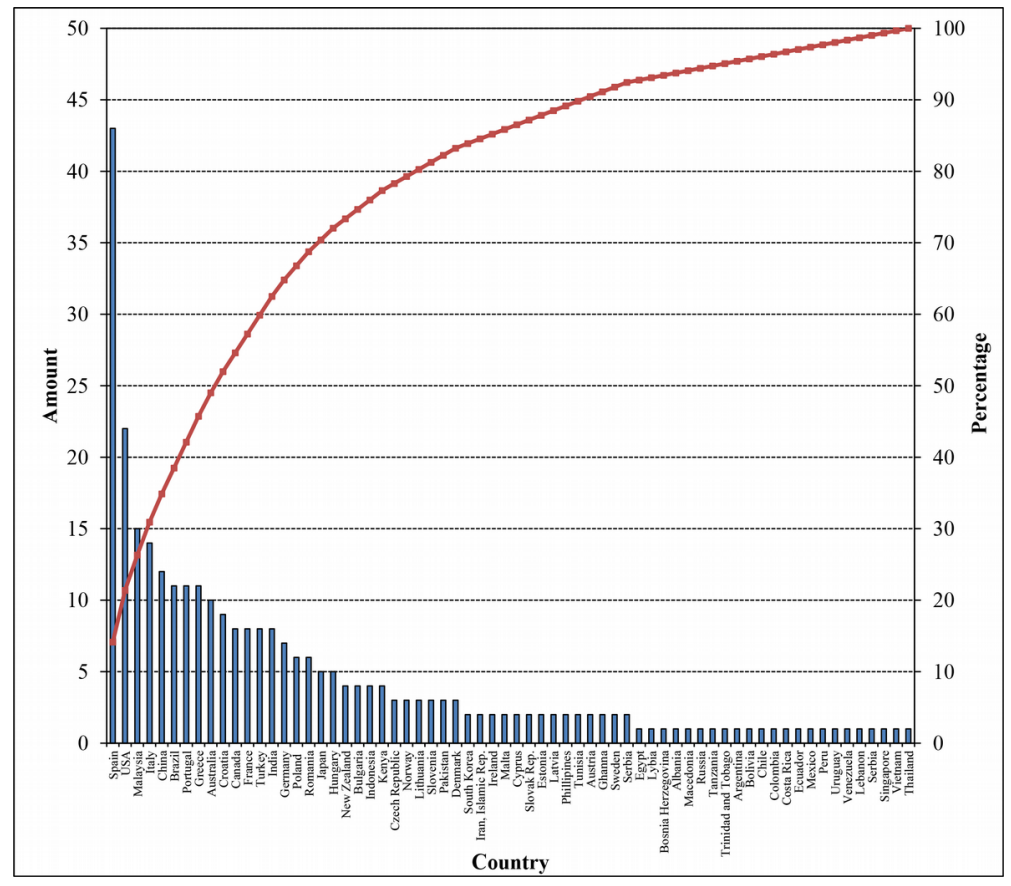

Figure 3. Country of origin of authors of articles with the topic circular MSC articles

Figure 4 shows the detail of the journal where the articles have been published. It is also clear that a few journals are highly represented, with Journal of Cleaner Production (20 articles), Total Quality Management and Business Excellence (15 articles), The TQM Journal (8 articles), International Journal of Production Economics (7 articles), International Journal of Quality \& Reliability Management (7 articles), Journal of Industrial Engineering and Management (5 articles), and Safety Science (5 articles), accounting, in total, for $38 \%$ of the total number of articles. 


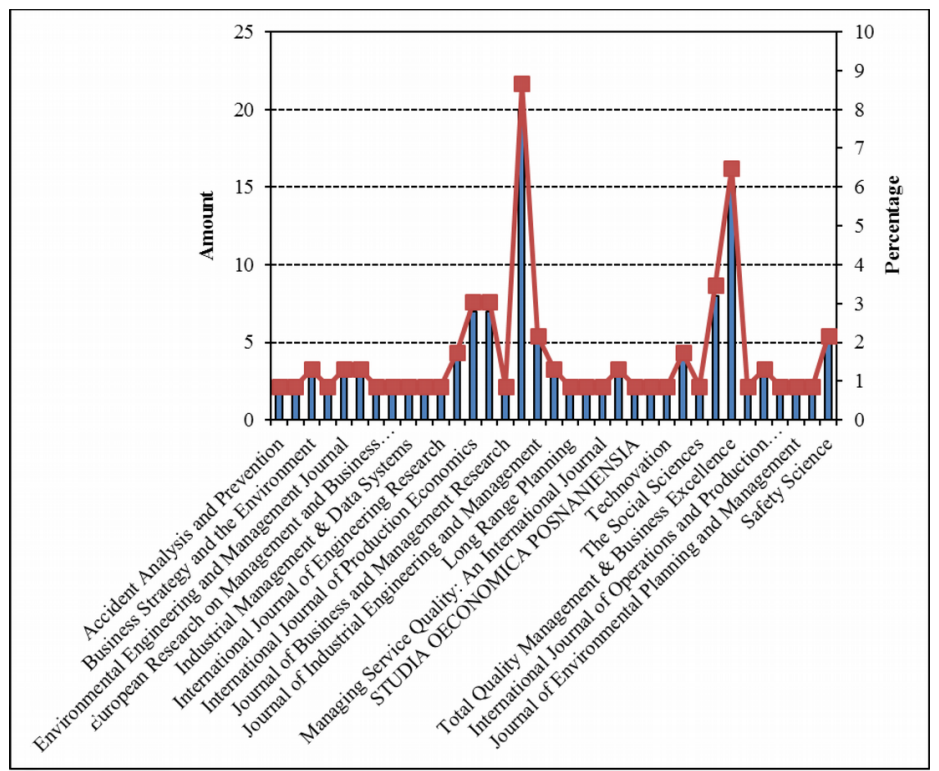

Figure 4. Distribution of the $\mathrm{N}^{\mathrm{o}}$ of articles per journals with at least 2 published articles

Concerning the number of citations there are some articles that have a considerable high number of citations (29 articles have more than 14 citations) as presented in Figure 5:

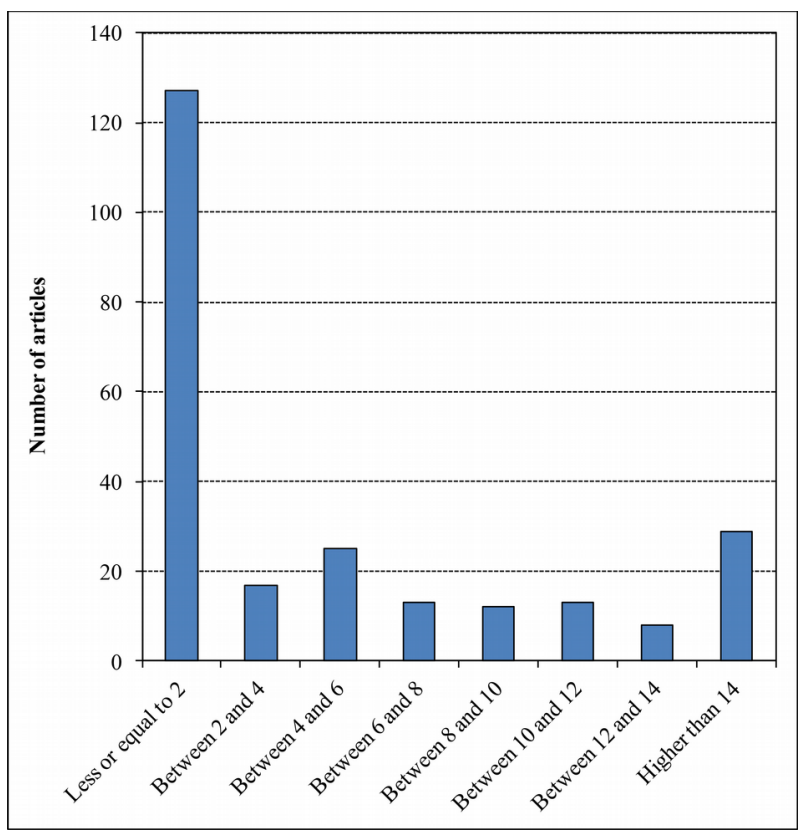

Figure 5. Distribution of the $\mathrm{N}^{\circ}$ of articles per number of citations 
In summary, the research is concentrated in Spain, USA, Malaysia, Italy, and China (41\% total articles), and in a few journals', indicating some players have taken the lead of the research in Management Systems Certification.

Analyzing the content of the published papers, $91 \%$ have a single country scope, while $50 \%$ address only one activity sector and the other half 2 or more sectors. Figure 6 represents the distribution of articles by macro, meso and micro level research, and the results show that the meso level scope is clearly dominant:

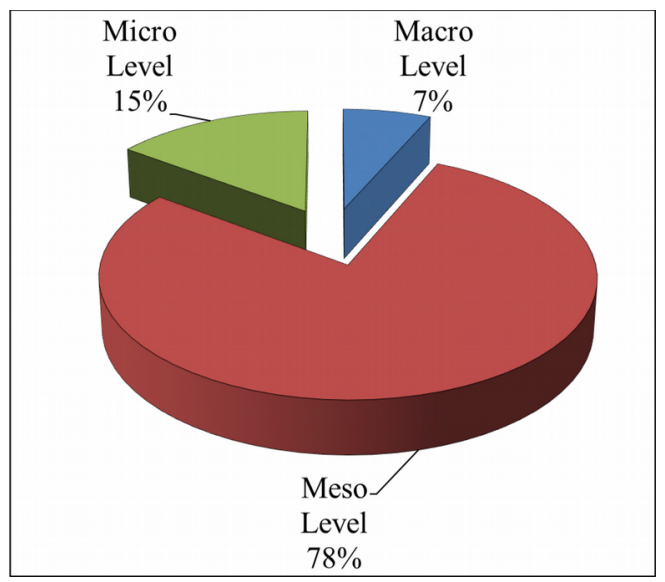

Figure 6. Scope level of MSC articles

ISO 9001 - Quality Management Systems and ISO 14001 - Environmental Management Systems are the two most disseminated ISO International Management System Standards. The following subsections address ISO 9001 and ISO 14001 and conclude with a comparison of the results from the two standards and the total.

\subsection{Comparison of ISO 9001 Quality Management System Certification and ISO 14001 Environmental Management Systems}

While ISO 9001: Quality management system (QMS) - Requirements, is the unquestionable number one MSS concerning the world number of certificates, with more than 1 million organizations certified worldwide (ISO Survey 2015, 2016), ISO 14001: Environmental management system (EMS) Requirements has considerable methodologic similarity with ISO 9001. The implementation of ISO 9000 series has contributed to the subsequent diffusion of ISO 14001, that has been growing steadily with more than 319 thousand certifications on a world basis, and a yearly growth of 8\% versus 2014 (ISO 
Survey 2015, 2016). The third ISO MSS in the ISO Survey 2015 of certification has approximately one tenth of certificates when compared to ISO 14001 (ISO 22000: Food safety management systems Requirements, with 32 thousand certificates). Following ISO 9001:2015 and ISO 14001:2015 editions, ISO decided all MSSs should follow a similar structure "the Annex SL Structure", so we believe this harmonization favors the implementation of Integrated Management Systems (Domingues, Fonseca, Sampaio \& Arezes, 2016) and the study of their similarities and differences. We therefore decided to focus and compare the research production of these two most widely adopted MSSs, performing a detailed analysis of the articles published from 1996 to April 2017, by journal, for Quality Management Systems Certification (QMSC) and Environmental Management Systems Certification (EMSC), and the results are presented in the Figures 7 and 8.

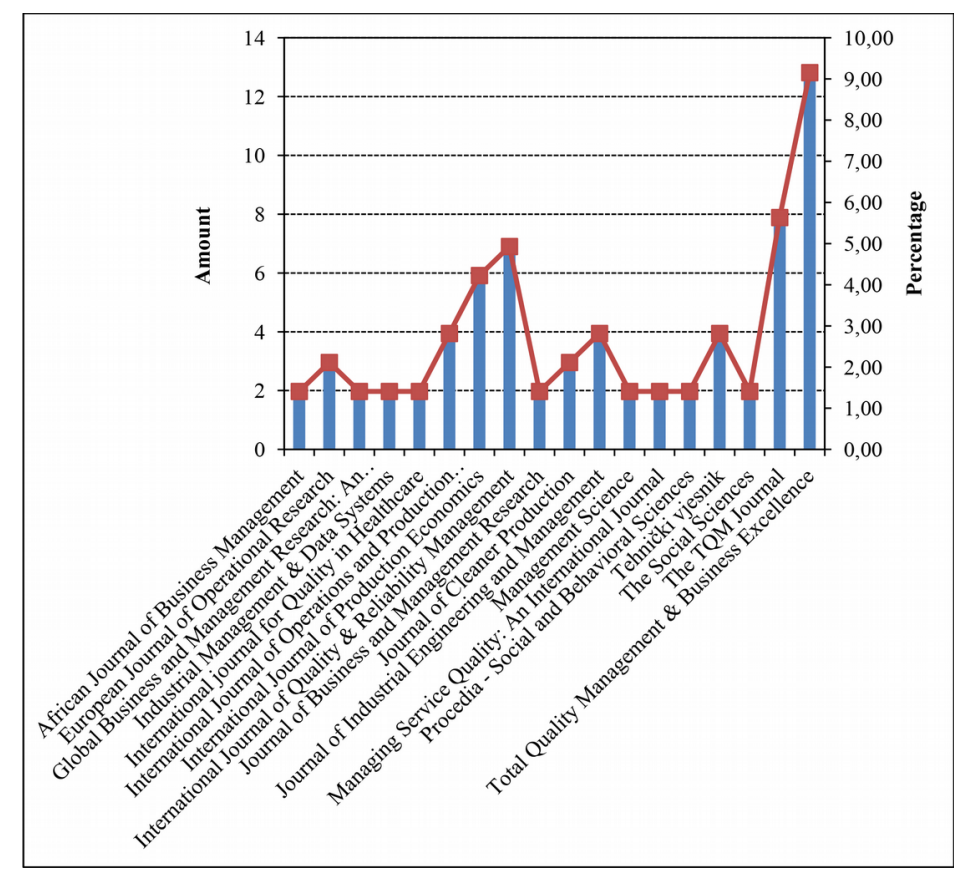

Figure 7. Journals of publication of articles with the topic ISO 9001 QMSC with at least 2 plublished articles 


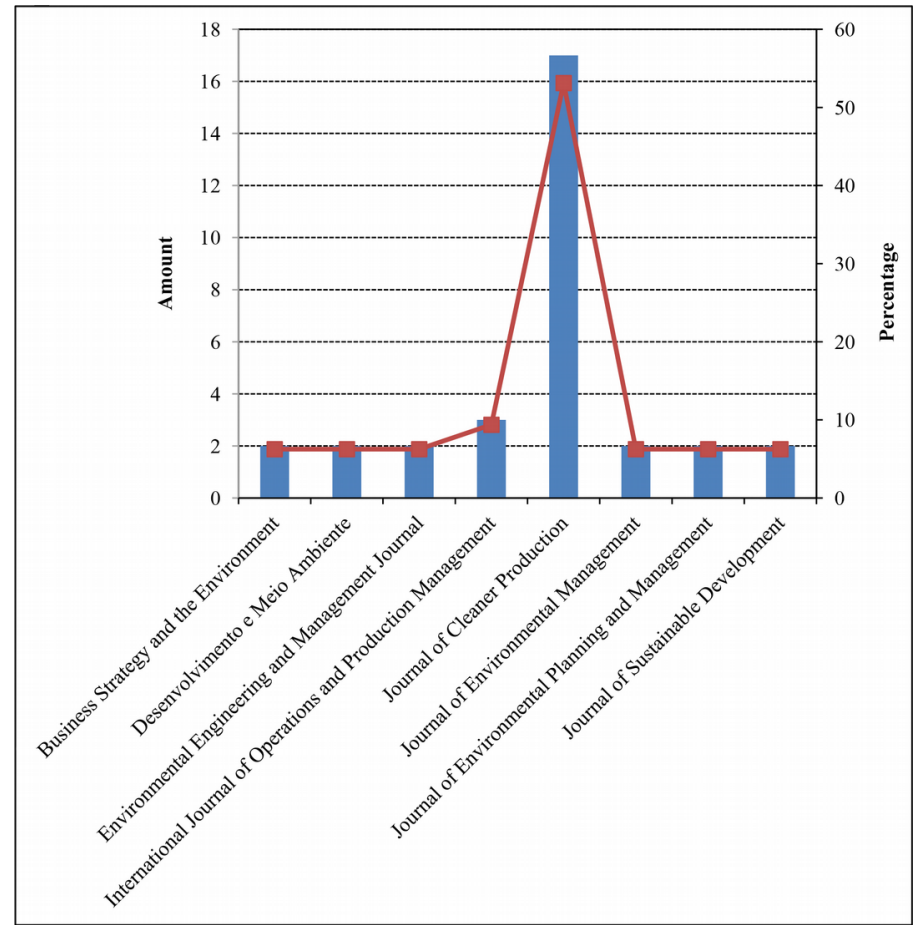

Figure 8. Journals of publication of articles with the topic ISO

14001 EMSC with at least 2 published articles

Table 2 presents the overall comparison of all studied dimensions.

\begin{tabular}{|c|c|c|c|}
\hline Dimension & ISO 9001 QMS & ISO 14001 EMS & Total MSC \\
\hline $\begin{array}{l}\mathrm{N}^{\mathrm{o}} \text { articles published } 2012 \text { to } \\
\text { April } 2017 \text { (\% total) }\end{array}$ & $101(63 \%)$ & $48(70 \%)$ & $\begin{array}{l}170(66 \%) \\
\text { Note: MS other than ISO } 9001 \text { and } \\
\text { ISO } 14001 \text { represented } 20 \% \text { of the } \\
\text { total of the } 2016 \text { articles }\end{array}$ \\
\hline Europe World share & $50 \%$ & $41 \%$ & $48 \%$ \\
\hline East Asia \& Pacific World share & $22 \%$ & $26 \%$ & $23 \%$ \\
\hline North America World share & $8 \%$ & $15 \%$ & $10 \%$ \\
\hline Top Country & Spain & Spain & Spain \\
\hline$\%$ articles from Top Country & $15.5 \%$ & $\begin{array}{l}11.5 \% \text { (closely followed by } \\
\text { USA with } 10.4 \% \text { ) }\end{array}$ & $14 \%$ \\
\hline Top 5 Countries & $\begin{array}{l}\text { Spain, Malaysia, USA, } \\
\text { Brazil, Italy }\end{array}$ & $\begin{array}{l}\text { Spain, USA, Canada, } \\
\text { France, China }\end{array}$ & Spain, USA, Malaysia, Italy, China \\
\hline $\begin{array}{l}\% \text { of articles from Top } 5 \\
\text { countries }\end{array}$ & $34 \%$ & $38 \%$ & $35 \%$ \\
\hline$\%$ Single sector & $51 \%$ & $42 \%$ & $50 \%$ \\
\hline$\%$ Single country & $92 \%$ & $90 \%$ & $91 \%$ \\
\hline$\%$ Meso Level & $76 \%$ & $80 \%$ & $78 \%$ \\
\hline Top Journal & $\begin{array}{c}\text { TQMBE - Total } \\
\text { Quality Management } \\
\text { \& Business Excellence } \\
\text { (9.15\% of total } \\
\text { articles) }\end{array}$ & $\begin{array}{l}\text { JCLEPRO - Journal of } \\
\text { Cleaner Production }(25 \% \\
\text { of total articles) }\end{array}$ & $\begin{array}{c}\text { JCLEPRO }(8.7 \%), \text { followed by } \\
\text { TQMBE }(6.5 \%)\end{array}$ \\
\hline
\end{tabular}

Table 2. Summary Comparison of ISO 9001 QMSC and ISO 14001 EMSC 
To assess the scientific content of the articles an analysis by keyword was made highlighting the similarities (Quality/Environment, ISO 9001/14001, Performance, Management Systems, Certification, Financial) and some differences (ISO 9001: ISO 14001, possible focus on integration; ISO 14001: more emphasis on benefits) and is presented in Figures 9 (ISO 9001 QMSC articles keywords) and 10 (ISO 14001 EMSC keywords).

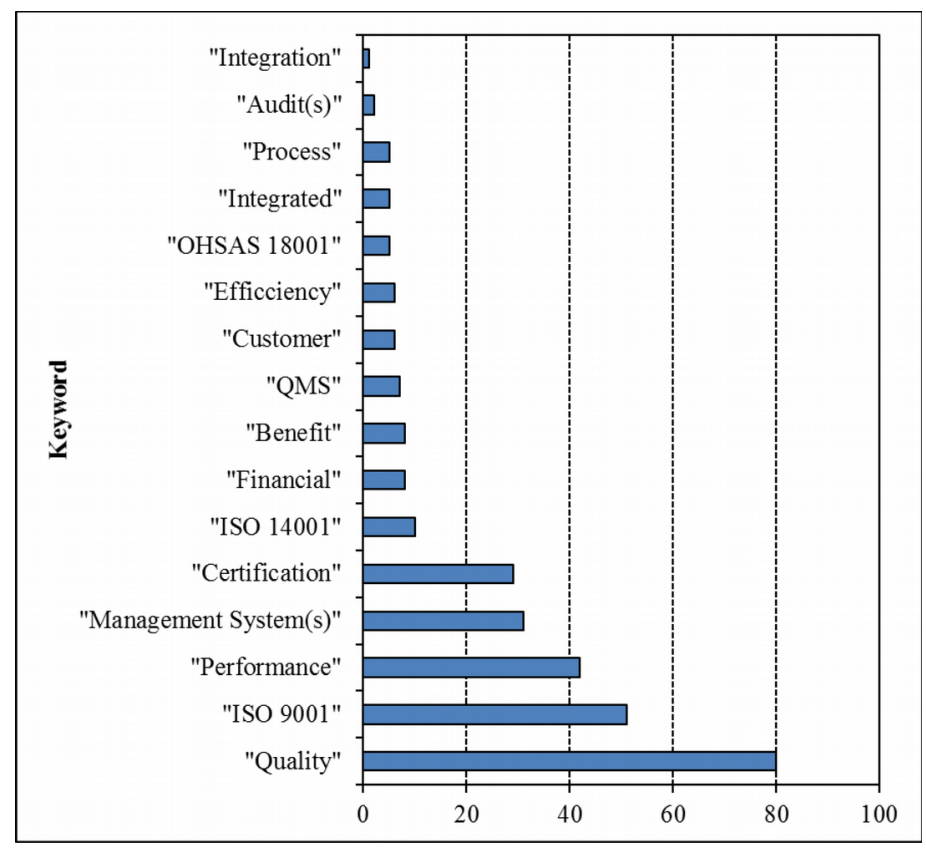

Figure 9. ISO 9001 QMSC articles keywords

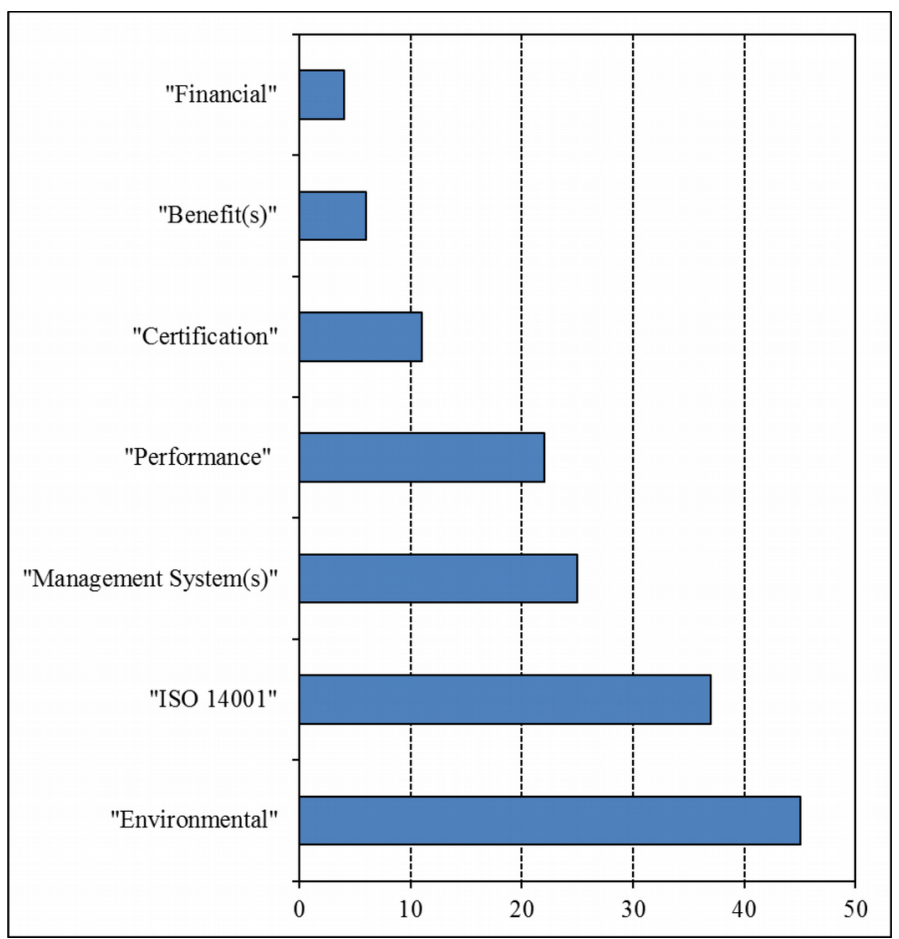

Figure 10. ISO 14001 EMSC articles keywords (authors elaboration) 


\subsection{Analysis of the Relationship between Management Systems Certification and Economic,} Financial or Stakeholder Results

To assess the level of support of the articles conclusions regarding "the existence of a positive relationship between Management System Certification (MSC) and economic, financial or stakeholder results, "the research outcomes (measured by results and scope) of all articles were analyzed according to the Likert Type scale presented in Table 1. The result of that analysis is summarized in Table 3.

\begin{tabular}{|l|r|r|r|r|}
\hline \multicolumn{1}{|c|}{ Research outcomes (measured by results and scope) } & $\begin{array}{c}\text { ISO } \\
9001\end{array}$ & $\begin{array}{c}\text { ISO } \\
14001\end{array}$ & $\begin{array}{c}\text { Other } \\
\text { MSS }\end{array}$ & $\begin{array}{c}\text { Total } \\
\text { MSS }\end{array}$ \\
\hline $\begin{array}{l}\text { 1. } 0 \% \text { (No evidence of positive relationship of MSC in economic, } \\
\text { financial or stakeholder results) }\end{array}$ & $10 \%$ & $11 \%$ & $10 \%$ \\
\hline $\begin{array}{l}\text { 2. } 25 \% \text { (Evidence of positive relationship of MSC in some of the } \\
\text { economic, financial or stakeholder results) }\end{array}$ & $59 \%$ & $55 \%$ & $60 \%$ \\
\hline $\begin{array}{l}\text { 3. } 50 \% \text { (Evidence of positive relationship MSC in at least half of the } \\
\text { relevant economic, financial and stakeholder results) }\end{array}$ & $20 \%$ & $21 \%$ & $12 \%$ \\
\hline $\begin{array}{l}\text { 4. } 75 \% \text { (Evidence of positive relationship of MSC in most of the relevant } \\
\text { economic, financial and stakeholder) results }\end{array}$ & $10 \%$ & $13 \%$ & $20 \%$ \\
\hline $\begin{array}{l}5.100 \% \text { (Evidence of strongly positive relationship of MSC in the } \\
\text { relevant economic, financial and stakeholder results) }\end{array}$ & $1 \%$ & $0 \%$ & $12 \%$ \\
\hline Mean value (1 to 5 scale) & 2.33 & 2.36 & 2.44 & 2.34 \\
\hline
\end{tabular}

Table 3. Evaluation scale to access benefits of MSC

These results are consistent with Tarí et al. (2012) supporting the view that the bibliographic analysis of the articles published from 1996 addressing the benefits of MSC support "the existence of a fairly positive relationship between Management System Certification (MSC) and economic, financial or stakeholder results, although there is dispersion and inconsistency in some results, as seen in Figure 11, that presents the distribution of the evaluation, for ISO 9001, ISO 14001, other Management Systems Standards (MSS) and the overall MSS. 


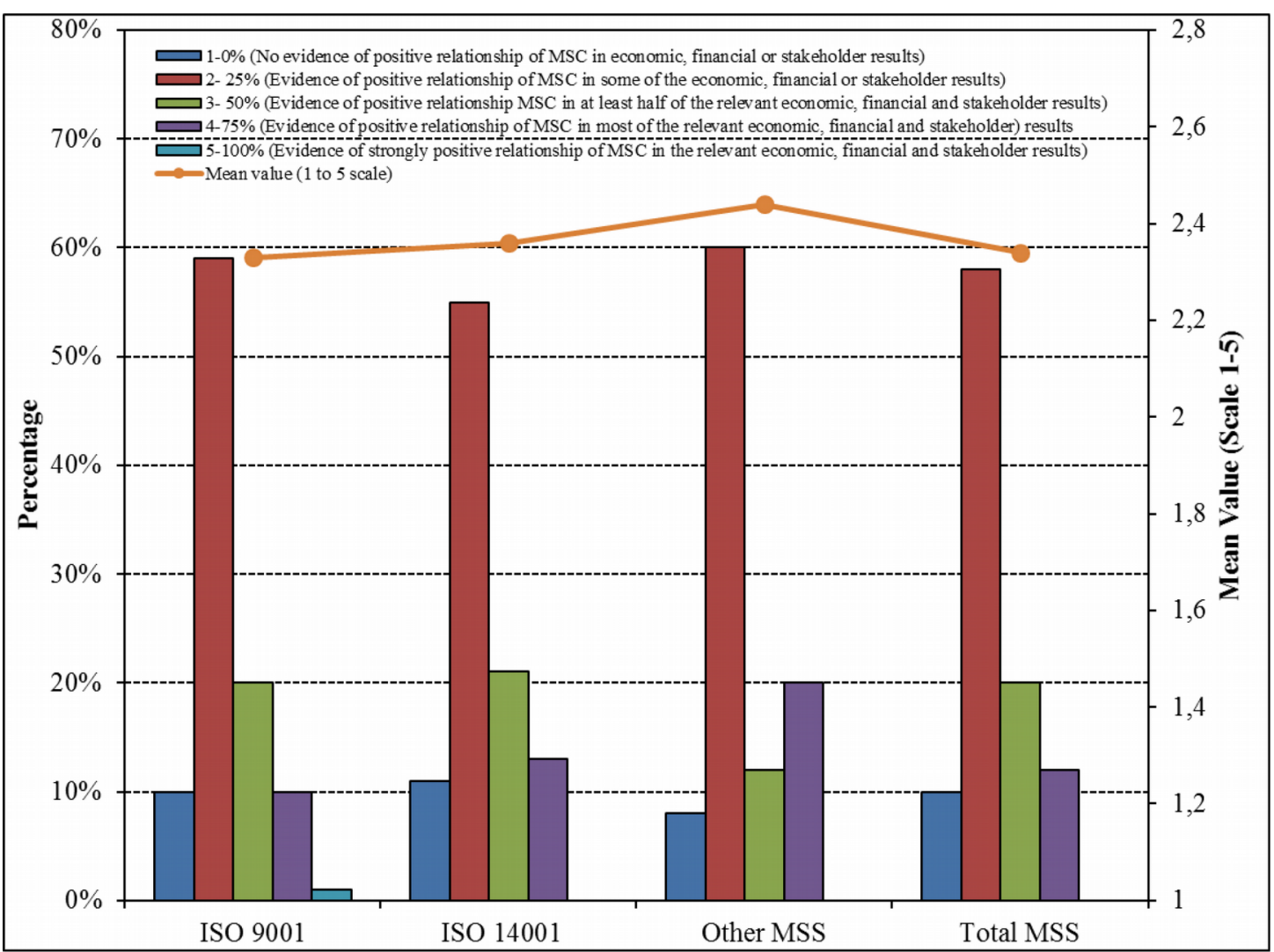

Figure 11. Results of the analysis of the relationship between Management Systems Certification and economic, financial or stakeholder results

\section{Discussion}

This paper carries out a literature review on the Management System Certification benefits to try to contribute to the clarification of its impacts for organizations. By applying a Bibliometric Review, a longitudinal time perspective is introduced analyzing the articles published since 1996, on the benefits of Management Systems Certification. The analysis of the countries of authors origin, keywords and journals are complemented with an evaluation of the research results.

Concerning the overall MSC articles, it is clear from Figure 1 that there is a steep increase in the number of publications since 1996. These articles originated mainly from Europe (48\%) followed by East Asia and Pacific (23\%). Spain is the leading country accounting for 14\%, and the top five is completed with USA, Malaysia, Italy, and China (35\% of total articles in MSC published between 1996 and April 2017). Spain is consistently in the top ranking of ISO 9001 and 14001 worldwide certifications, showing a virtuous cycle, the higher the number of certifications, the greater the certification intensity and the more intense and recognized is the academic research network (Marimon, Casadeús \& Heras, 2010). Some reasons that might explain this finding is the export intensity of Spain, the incentives available to companies and researchers, the existence of strong and reliable national certification (e.g., AENOR) and 
accreditation bodies (ENAC), competent Researchers and supporting Universities, and the cumulative adoption of innovations, as explained by Teece (1980).

From Figure 4 there are two leading journals concerning the publications of MSC research, Journal of Cleaner Production and Total Quality Management and Business Excellence journal. The top 7 journals account for $38 \%$ of the total numbers of articles: Journal of Cleaner Production (20 articles), Total Quality Management and Business Excellence (15 articles), The TQM Journal (8 articles), International Journal of Production Economics (7 articles), International Journal of Quality \& Reliability Management (7 articles), Journal of Industrial Engineering and Management (5 articles), and Safety Science (5 articles). Some articles also have a considerable high number of citations (Figure 5).

Considering the contents of the published articles, $91 \%$ address only one country and approximately half only one activity sector. The meso level of analysis is the most common (79\%).

By comparing the research on ISO 9001 Quality Management Systems Certification (QMSC) with ISO 14001 Environment Management Systems Certification (EMSC) it is possible to conclude that both research streams show a steady growth trend, and evidence similar key words resemblances. However, there are some differences such as TQM\&BE is the leading journal in the QMSC field, while JCLEPRO dominates EMSC. Spain is the unquestioned leader in country authors countries of origin, but there are some differences in the World Macro Regions contributions, e.g. North America as a higher contribution for the articles on EMSC.

And finally, as presented in Table 3, the bibliographic analysis supports the view that there is "a fairly positive relationship between Management System Certification (MSC) and economic, financial or stakeholder results", although some results dispersion and inconsistency should be acknowledged. Differences in the interpretation, application, and certification of the ISO MSS, the use of different research methods, a weak reliability of some results and conclusions, contingency time factors, and research articles that are not always comparable, might be explaining reasons for this. 


\section{Conclusions}

The aim of this paper was to conduct a systematic review of the scientific articles published from 1996 to April 2017 addressing the benefits of Management Systems Certification. The results of the analysis of the selected papers evidence a steep increase in the number of publications, that mainly originate from Europe (48\%) and East Asia and Pacific (23\%), with Spain as the leading country accounting for 14\% of the number of articles on MSC published between 1996 and April 2017. There are also insights that the research is now open to other Management Systems either than Quality and Environment (ISO Survey 2015, 2016), as is the case of MSSs such as ISO 50001: Energy management systems -Requirements with guidance for use (12 thousand certificates, with a 77\% yearly growth), ISO 27001: Information security management systems - Requirements (28 thousand certificates, with a 20\% yearly growth) and ISO 22000 : Food safety management systems - Requirements (32 thousand certificates with a 16\% yearly growth). From a pragmatic point of view, the proliferation of ISO 9001/14001 "like" MSSs (although with different intents) may be a strong argument for its diffusion and application benefits.

Journal of Cleaner Production (EMSC) and Total Quality Management and Business Excellence journal (QMSC) are the leading journals for articles on MSC and the most used keywords are “Quality/Environment", “ISO 9001/14001”, "Performance", "Management Systems” and “Certification”.

The systematic review of the selected papers shows that the Management Systems adoption and certification bring fairly positives benefits (average 2,34 in a 1 to 5 Likert type scale) for the certified organizations, although some variations are observed.

Some avenues for future research are; the reliability and validation of measures; sampling and biases errors; use of control and moderating and mediating variables; consideration of time and situational contingencies; and the search for explanations for cause and effect relationships.

The results of this research support the view that the investigation of Management Systems Certification benefits is indeed an issue of high academic and practitioners interest. This research, although subject to some subjective evaluation of the authors, and acknowledging that the research articles are not always comparable, aims to give some insights for this continuous research field. 


\section{References}

Boiral O. (2012). ISO 9000 and organizational effectiveness: A systematic review. Quality Management Journal, 19(3), 16-37.

Boiral, O., \& Roy, M. (2007). ISO 9000: Integration rationales and organizational impacts. International Journal of Operations and Production Management, 27(2), 226-247. https://doi.org/10.1108/01443570710720630

Casadesús, M., Heras, I., \& Ochoa, C. (2000). The benefits of the implementation of ISO 9000 normative: Empirical research in the Spanish companies. Proceedings of the Fifth world conference on production and operations management [CD-ROM].

De Bellis, N. (2009). Bibliometrics and Citation Analysis. The Scarecrow Press. Lanham.

Domingues, J.P.T., Fonseca, L., Sampaio, P., \& Arezes, P.M. (2016). Integrated versus nonintegrated perspectives of auditors concerning the new ISO 9001 revision. IEEE International Conference on Industrial Engineering and Engineering Management, 866-870;

Fetscherin, M., \& Heinrich, D. (2015). Consumer brand relationships research: a bibliometric citation meta-analysis. Journal Business Research, 68, 380-390. https://doi.org/10.1016/j.jbusres.2014.06.010

Fonseca, L., (2015a). From Quality gurus and TQM to ISO 9001:2015: a review of several quality paths. International Journal for Quality Research, 9(1), 167-180.

Fonseca, L.M., (2015b). Relationship between ISO 9001 certification maturity and EFQM Business Excellence Model results. Quality, Innovation and Prosperity, 19(1), 85-102. https://doi.org/10.12776/QIP.V19I1.556

Herrero-Prieto, L.C. (2009). La investigación en Economía de la cultura en España: Un estudio bibliométrico. Estudios de Economía Aplicada, 27(1), 35-62.

International Organization for Standardization (ISO) (2016). ISO Survey 2015. Available at: http://www.iso.org.

Karapetrovic, S., Casadesus-Fa, M., \& Heras-Saizarbitoria, I., (2010). What happened to the ISO 9000 lustre? An eight-year study. Total Quality Management, 21(3), 245-267.

https://doi.org/10.1080/14783360903553149

Kim, J., McMillan, S.J. (2008). Evaluation of internet advertising research: A bibliometricanalysis of citations from key sources. Journal of Advertising, 37(1), 99-112. http://dx.doi.org/10.2753/JOA00913367370108 
Llopis, J., \& Tari, J. (2003). The importance of internal aspects in quality improvement. International Journal of Quality \& Reliability Management, 20(3), 304-324. https://doi.org/10.1108/02656710310461314

Marimon, F., Casadeús, M., \& Heras, I. (2010). Certification intensity of the leading nations in ISO 9000 and ISO 14000 standards. International Journal of Quality and Reliability Management, 27(9), 1002-1020. https://doi.org/10.1108/02656711011084800

Martínez-Costa, M., Martínez-Lorente, A., \& Choi, T. (2008). Simultaneous consideration of TQM and ISO 9000 on performance and motivation: An empirical study of Spanish companies. International Journal of Production Economics, 113(1), 23-39. https://doi.org/10.1016/j.ijpe.2007.02.046

Prajogo, D. (2011). The role of firms motives in affecting the outcomes of ISO 9000 adoption. International Journal Operations and Production Management, 31(1), 78-100. https://doi.org/10.1108/01443571111098753

Ramos-Rodríguez, A.R., \& Ruiz-Navarro, J. (2008). Base intelectual de la investigación en creación de empresas: un estudio bibliometrics. Revista Europea de Dirección y Economía de la Empresa. 17(1), 13-38.

Tarí, J.J., Molina-Azorín, J.F., \& Heras, I., (2012). Benefits of the ISO 9001 and ISO 14001 standards: A literature review. Journal of Industrial Engineering and Management, 5(2), 297-322. https://doi.org/10.3926/jiem.488

Teece, D. (1980). The diffusion of an administrative innovation. Management Science, 26(5), 464-470. https://doi.org/10.1287/mnsc.26.5.464

Journal of Industrial Engineering and Management, 2017 (www.jiem.org)

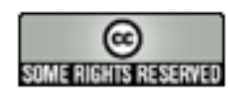

Article's contents are provided on an Attribution-Non Commercial 3.0 Creative commons license. Readers are allowed to copy, distribute and communicate article's contents, provided the author's and Journal of Industrial Engineering and Management's names are included. It must not be used for commercial purposes. To see the complete license contents, please visit http://creativecommons.org/licenses/by-nc/3.0/. 